\title{
Polymyxin B2 Sulfate
}

National Cancer Institute

\section{Source}

National Cancer Institute. Polymyxin B2 Sulfate. NCI Thesaurus. Code C61899.

The sulfate salt form of polymyxin B2, a polypeptide obtained from Bacillus polymyxa strains with antimicrobial activity. Polymyxin B2 exerts its antimicrobial effect through its cationic detergent action on cell membranes. Specifically, this antibiotic binds to the negatively charged site in the lipopolysaccharide layer of the bacterial cell membrane via electrostatic affinity with the positively charged amino groups in the cyclic peptide portion. Subsequently, the fatty acid portion of polymyxin B2 dissolves in the hydrophobic region of the bacterial cell membrane. This results in an alteration in cell membrane structure, disruption of cell wall integ rity and an increase in permeability for water and molecules. This will eventually lead to bacterial cell death. 